\title{
Temporal and Spatial Characteristics of Rice Photosynthetic Potential in Liaoning Province for 30 Years
}

\author{
Min $\mathrm{Li}^{1, \mathrm{a}}$, Yulu Sun ${ }^{1, \mathrm{~b}}$, Xianjin Zhu ${ }^{1, \mathrm{c} .{ }^{*}}$, Junming $\mathrm{He}^{1, \mathrm{~d}}$, \\ Benqing $\mathrm{Su}^{1, \mathrm{e}}$ and Chong Wang ${ }^{1, \mathrm{f}}$ \\ ${ }^{1}$ Agricultural College, Shenyang Agricultural University, Shenyang 110000, China \\ a790061931@qq.com, b540840050@qq.com, cxianjin1985@163.com, \\ d1012508291@qq.com, ${ }^{\mathrm{e}} 553185865 @ q q . c o m,{ }^{\dagger}$ 379258525@qq.com \\ *The corresponding author
}

\section{Keywords: Rice; Photosynthetic Potential; Space-Time Changes; Liaoning Province}

\begin{abstract}
The estimation of photosynthetic potential of rice can reflect the upper limit of its potential of production, and it is of great significance to improve the yield of grain per unit and ensure the security of grain in the future. From the point of view of solar radiation and sunshine hours, the photosynthetic potential of rice in 24 meteorological stations in Liaoning Province during the growth period from May to September was estimated by using Huang Bingwei theory. The results show that: during the study period, the average photosynthetic potential productivity of rice in Liaoning province was $25168 \mathrm{~kg} \cdot \mathrm{hm}^{-2}$, which showed a decreasing trend over time and the decreasing rate was $39.25 \mathrm{~kg} \cdot \mathrm{hm}^{-2} \cdot(10 \mathrm{a})^{-1}$. The spatial variation shows a trend of high in the northwest and low in the southeast.
\end{abstract}

\section{Foreword}

The estimation of crop productive potential can be divided into three stages: light, temperature and water, photosynthetic production potential is the basis for the ultimate production potential of crops. As a thermophilic crop, the utilization rate of photosynthetic radiation is a necessary condition for the growth and development of rice. Liaoning Province is one of the main grain producing areas in the north and an important commodity grain base[1].Rice is the second largest food crop in Liaoning Province[2], the planting area accounts for about $17 \%$ of the total grain planting area in Liaoning Province, and the yield is about $23 \%$ of the total grain production in Liaoning Province[3],therefore, its production potential has been paid much attention. The purpose of calculating photosynthetic potential is to explore the effect of light energy efficiency on rice production. At present, many scholars estimate the photosynthetic potential of rice in different regions [4-6]. It provides theoretical basis for evaluating the potential of rice production, reasonably developing rice resources and promoting real productivity in this area.

\section{Materials and Methods}

Photosynthetic production potential. Photosynthetic production potential (YQ) refers to the theoretical yield of a crop within unit time and unit areformed by light energy resources without considering other factors. The formula is:

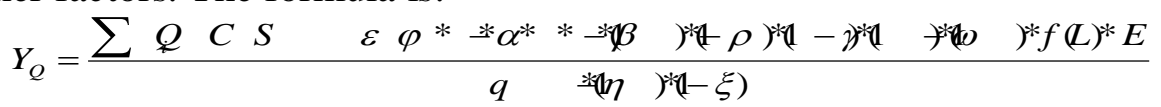

$Y Q$ is the photosynthetic potential per unit area. $\left(\mathrm{kg} \cdot \mathrm{hm}^{-2}\right) ; C$ is the unit conversion coefficient with a value of $10000 ; \sum \Theta$ is the total radiation amount in the growing period [7-10] can be obtained by calculating the percentage of sunshine in climatology $\left(\mathrm{MJ} \cdot \mathrm{m}^{-2}\right)$. Other correlation coefficients are shown in table 1. 


$$
Q=(a+b s) Q_{s}
$$

In the formula, $Q$ is the total solar radiation; $Q s$ is astronomical radiation $\left(\mathrm{MJ} \cdot \mathrm{m}^{-2}\right), s$ is the percentage of sunshine (\%); a and $b$ are empirical constants, here $a=0.25, b=0.5$.

Table 1. The meaning and value of the parameters of rice photosynthetic potential

\begin{tabular}{ccc}
\hline Parameter & Meaning & Value \\
\hline $\mathrm{S}$ & Proportion of photosynthetic fixation capacity of crops & 0.9 \\
$\varepsilon$ & Photosynthetic effective radiation ratio & 0.49 \\
$\varphi$ & Light quantum conversion efficiency & 0.22 \\
$\alpha$ & Plant population reflectivity & 0.06 \\
$\beta$ & Plant population transmissivity & 0.06 \\
$\rho$ & Radiation interception rate of non-photosynthetic organs in crops & 0.08 \\
$\gamma$ & Ratio of light beyond the saturation point of light & 0.05 \\
$\omega$ & Respiratory consumption as a percentage of photosynthetic & 0.33 \\
$f(\mathrm{~L})$ & products & 0.56 \\
$\mathrm{E}$ & Dynamic change of crop leaf area & 0.4 \\
$\eta$ & Crop economic coefficient & 0.15 \\
$\xi$ & Moisture content of mature crops & 0.08 \\
$\mathrm{q}$ & Crop ash rate & 17.5 \\
\hline
\end{tabular}

Data processing. The equation of rice photosynthesis potential and longitude, latitude and altitude were established, and the spatial distribution of rice productivity in Liaoning Province from 1987 to 2016 was obtained by using ArcGIS to carry out Kriging space interpolation. Spss was used to analyze the significance between time and yield. The change trend was obvious by $\alpha=$ 0.05 significance test, and the change trend was extremely obvious by $\alpha=0.01$ significance test. Mann-Kendall method was used to analyze the variation of rice photosynthesis production potential over many years.

\section{Results and Analysis}

Time distribution of photosynthetic production potential. The change in photosynthetic production potential over time between 1987 and 2016 in Liaoning Province is shown in Fig. 1(a).The potential for photosynthetic production during the growth period of rice in the past 30 years ranged from 23000 to $27000 \mathrm{~kg} \cdot \mathrm{hm}^{-2}$. Among them, the average photosynthetic production potential was $25168.08 \mathrm{~kg} \cdot \mathrm{hm}^{-2}$, and the fluctuation between years was large. The maximum value appeared in 2002, which was $26521.23 \mathrm{~kg} \cdot \mathrm{hm}^{-2}$, and the minimum value appeared in 2005 , which was $23738.58 \mathrm{~kg} \cdot \mathrm{hm}^{-2}$, with a difference of $2782.45 \mathrm{~kg} \cdot \mathrm{hm}^{-2}$. According to the meteorological data, the sunshine hours in the rice growing period in Liaoning Province in 2002 were higher than those in other years, so the total solar radiation was higher than that in other years, which promoted the development of rice photosynthetic potential. According to the trend line, the average photosynthetic potential decreased slowly with time, but the decreasing trend was not obvious, the average decline range was $39.25 \mathrm{~kg} \cdot \mathrm{hm}^{-2} \cdot 10 \mathrm{a}^{-1}$. According to $\mathrm{MK}$ mutation test the photosynthetic production potential of Fig. 1(b).Liaoning Province was mutated in 2000 and 2012 respectively. Therefore, the change of photosynthetic production potential was divided into three stages: from 1987 to 2000, the photosynthetic potential of rice increased slowly at the rate of 67.51 $\mathrm{kg} \cdot \mathrm{hm}^{-2} \cdot(10 \mathrm{a})^{-1}$, without 0.05 significant test, the rising trend was not significant. From 2001 to 2012 , the photosynthetic potential decreased at the rate of $770.18 \mathrm{~kg} \cdot \mathrm{hm}^{-2} \cdot(10 \mathrm{a})^{-1}$, showing a significant downward trend, while the photosynthetic potential of rice increased steadily since 2013, but the rate of increase was not significant. Correspondingly, since 1987, the total solar radiation in 
Liaoning Province from May to September of the rice growing season has also decreased slowly at $4.776 \mathrm{MJ} \cdot \mathrm{m}^{-2} \cdot(10 \mathrm{a})^{-1}$. Among them, the total solar radiation increased slowly from 1987 to 2000, and the increase was $8.22 \mathrm{MJ} \cdot \mathrm{m}^{-2} \cdot(10 \mathrm{a})^{-1}$. From 2001 to 2012 , the total solar radiation decreased at the rate of $93.93 \mathrm{MJ} \cdot \mathrm{m}^{-2} \cdot(10 \mathrm{a})^{-1}$, Since 2013 , the solar radiation of rice growing season in Liaoning Province began to rise steadily, rising by $24.06 \mathrm{MJ} \cdot \mathrm{m}^{-2} \cdot(10 \mathrm{a})^{-1}$, but the whole solar radiation was still decreasing.
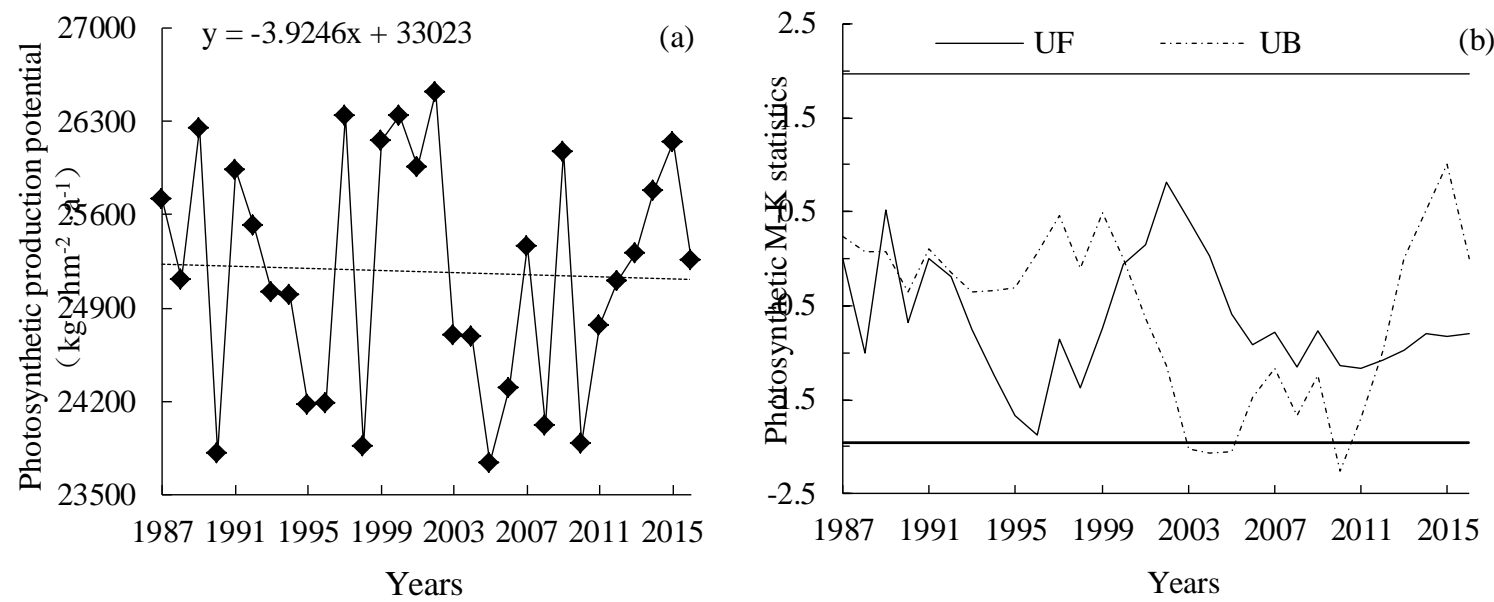

Figure 1. Temporal trend of photosynthetic production potential of rice from 1987 to 2016 and MK test

Space distribution of photosynthetic production potential. As shown in Fig. 2(a), the spatial distribution of rice photosynthetic production potential in Liaoning province in the last 30 years is in a trend of increasing gradient from southeast to northwest, and the overall photosynthetic potential is between $22000 \sim 27000 \mathrm{~kg} \cdot \mathrm{hm}^{-2} \cdot(10 \mathrm{a})^{-1}$, Among them, the low value area of photosynthetic production potential is located in the hilly region of southeast Liaoning, such as Hengren, Kuandian, Xiuyan, Dandong station, the range is between 22400 and $24400 \mathrm{~kg} \cdot \mathrm{hm}^{-2}$, Qingyuan, Zhuanghe ,Fushun, Benxi area is between 24800 and $25200 \mathrm{~kg} \cdot \mathrm{hm}^{-2}$, the lowest value is Dandong $22705.81 \mathrm{~kg} \cdot \mathrm{hm}^{-2}$; The central plain and western Liaoning Corridor area are the high value distribution area of Liaoning photosynthetic potential, which is above $\mathrm{kg} \cdot \mathrm{hm}^{-2}$. Among them, there are a large area around Kaiyuan, Xinmin, Shenyang and Wa fangdian stations in the central part of Liaoning Province and the west of Suizhong, the photosynthetic production potential is from 25200 to $25600 \mathrm{~kg} \cdot \mathrm{hm}^{-2}$, the west area of Fuxin, Jianping county Jinzhou, Yingkou and Dalian's photosynthetic production potential is from 25600 to $26500 \mathrm{~kg} \cdot \mathrm{hm}^{-2}$, and the highest value is $26347.23 \mathrm{~kg} \cdot \mathrm{hm}^{-2}$ in Jianping county. As a whole, the spatial distribution of photosynthetic potential in Liaoning Province was not different in 30 years.

From the spatial distribution of climatic tendency rate Fig. 2 (a), it can be seen that the photosynthetic potential of nearly $67 \%$ of the stations in Liaoning Province showed a decreasing trend during the period of study. Among them, 25\% of the sites passed the 0.01 significance test ,most of them were distributed in large areas of western Liaoning, and $6.25 \%$ of the sites passed the 0.05 significant test; Yingkou had the highest decline rate of $-628.28 \mathrm{~kg} \cdot \mathrm{hm}^{-2} \cdot(10 \mathrm{a})^{-1}$.However, the photosynthetic potential of $33 \%$ sites in the whole province is on the rise, among which only Benxi and Zhuanghe have passed the 0.01significant test, and the maximum rising rate of Benxi is $980.68 \mathrm{~kg} \cdot \mathrm{hm}^{-2} \cdot(10 \mathrm{a})^{-1}$. Therefore, the decrease of photosynthetic radiation has some advantages and disadvantages to the rice production in Liaoning Province, but on the whole, it is not conducive to the rice production in Liaoning Province, and the negative effect is greater than the positive effect.

It can be seen from the sliding average of photosynthetic potential in 10 years: from 1987 to 1996, the photosynthetic potential high area of rice was located in the semi-arid area of western Liaoning and the coastal area of southern Liaoning (Fig. 2. b) with a maximum of $26745 \mathrm{~kg} \cdot \mathrm{hm}^{-2}$, 
low value area is located in the mountain area of Liaodong and the lowest value was $23217 \mathrm{~kg} \cdot \mathrm{hm}^{-2}$; Comparison of 1987-1996, in the 1997-2006 year, the high value area of rice photosynthetic potential has spread to the East (Fig. 2. c). The photosynthetic potential of the central region and the southern part of Liaoning increased, but there was no difference in the low value area. Compared to the period of 1987-1996 and 1997-2006, the range of photosynthetic potential of rice in Liaoning Province decreased significantly from 2007 to 2016 (Fig. 2. d), the high value region obviously retreated to the western part of Liaoning, while the low value area of the east retreated to the east, showing a small increase trend. Therefore, the photosynthetic potential of rice decreased in 1987-2016, and the decrease in 2007-2016 was obviously higher than that in the previous two stages, and the decrease of photosynthetic potential in western Liaoning was higher than that in eastern Liaoning.
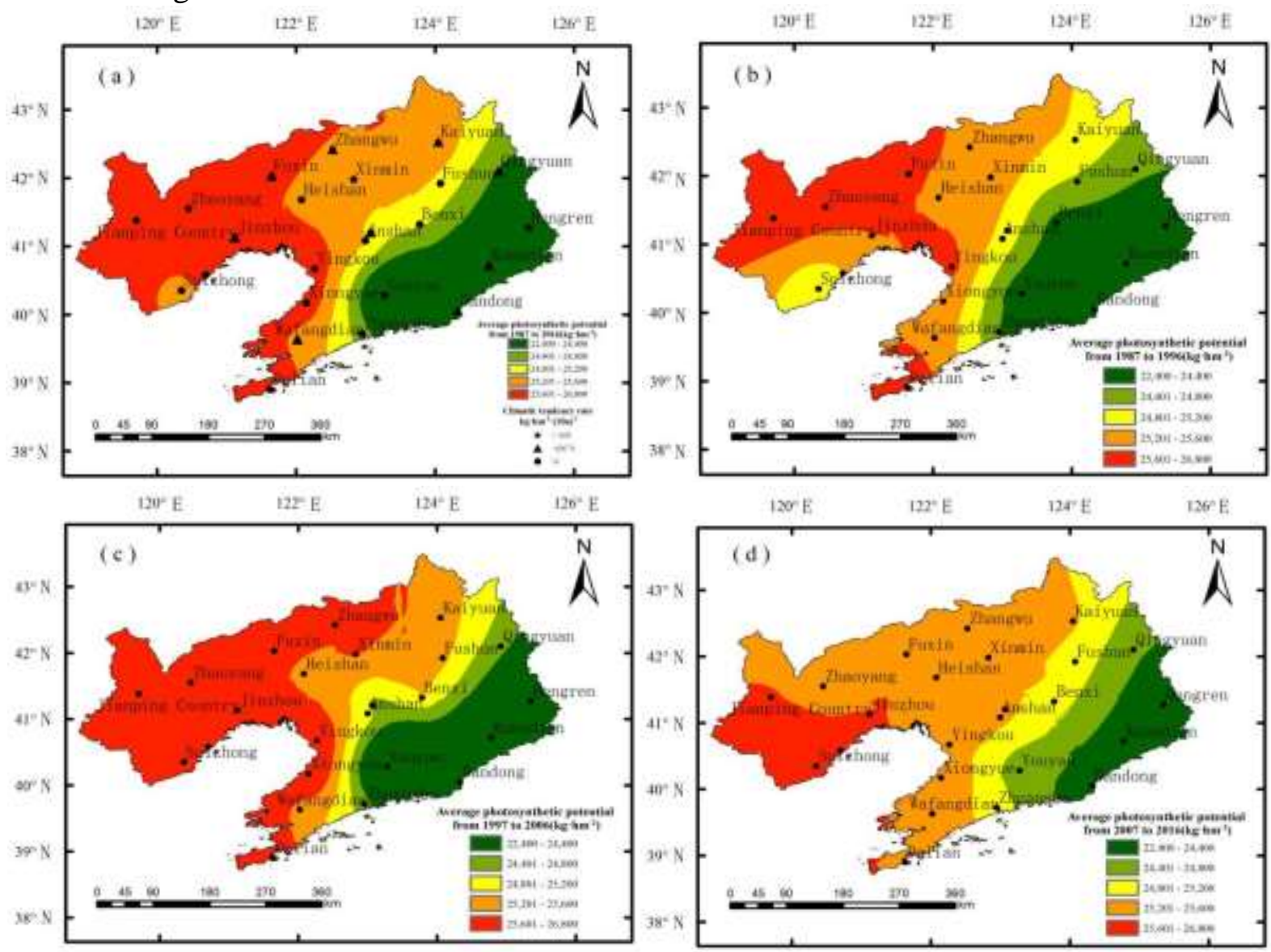

Figure 2. Spatial distribution of photosynthetic production potential and climatic tendency of rice from 1987 to 2016 and 10-year sliding average

\section{Discussion}

During the study period, the temporal and spatial variation of photosynthetic potential of rice was consistent with that of radiation. In the past 30 years, the decrease of total solar radiation has led to the decrease of photosynthetic efficiency and the decrease of photosynthetic potential of rice, which has a significant negative effect on rice yield, which is consistent with the previous research results [11]. At present, the exploration of the photosynthetic potential of rice is still improving. Because the climatic conditions, soil conditions, rice varieties and so on have some deviations, the utilization rate of light energy of rice is also different. Therefore, it is an important task in the future research to improve the variety and combine the local conditions to grow rice to promote the increase of yield and the efficiency of light energy utilization. 


\section{Conclusion}

In this study, the mechanism method was used to calculate the potential of rice photosynthesis in Liaoning Province from 1987 to 2016 and used the MK mutation test and Kriging space interpolation to analyze its spatiotemporal variation characteristics. In terms of time distribution, the average photosynthetic potential of rice in Liaoning Province ranged from $23000 \mathrm{~kg}$ to 27000 $\mathrm{kg} \cdot \mathrm{hm}^{-2}$, which showed an overall downward trend, and the decreasing rate was 39.25 $\mathrm{kg} \cdot \mathrm{hm}^{-2} \cdot(10 \mathrm{a})^{-1}$; MK mutation occurred in 2000 and 2012, and the potential of photosynthetic production did not increase significantly before 2000 and after 2012 but decreased significantly between 2001 and 2011. In terms of space distribution, The photosynthetic potential is high in the northwest and low in the southeast. The photosynthetic production potential of $67 \%$ of the sites is decreasing over time, the reduction range is relatively large in the west of Liaoning and the eastern part of Liaoning Province.

\section{Acknowledgements}

This research was supported by the National Natural Science Foundation of China (31500390, and 41503078), scientific and technological projects of Shenyang (18-015-7-25), and general scientific research project of Department of Education of Liaoning province (LSNYB201603) .

\section{References}

[1] L.P. Yan, Z.D. Wang and X.L. Lai. Analysis of Grain Production Capacity in Liaoning Province[J].Jiangsu Agricultural Sciences,Vol.42(2014)No .1,p.415.(in Chinese)

[2] Y.D. Li,S.G. Hou and H.X. Lin. Analysis of Potential Yield Increase of Rice Production in Liaoning Province[J].Liaoning Agricultural Sciences,.Vol.2(2009)No .2,p.48.(in Chinese)

[3] S.G. Hou, G.M. Sui and X.Q. Ma. Status and Prospect of Rice Industry Development in Liaoning Province[J].Northern Rice,Vol.42(2012)No .5,p.70.(in Chinese)

[4] B. Zhang. Estimation of Rice Climatic Productivity in Guizhou Province[C]. Chinese Meteorological Society. The 34th Annual Meeting of the Chinese Meteorological Society S12 Promotion of Meteorological Science and Technology Level and Guarantee of Agricultural Disaster Reduction and Efficiency Improvement. (Guizhou, 2017),Vol.1 p.10.

[5] D. Liu and Y.C. Li. Characteristics of spatial-temporal of late rice production potential in Jiangxi Province under background of climate change[J].Southwest China Journal of Agricultural Sciences. Vol.31(2018)No .1,p.184.(in Chinese)

[6] X.F. Li , H.Y. Zhao and H.X. Zhu. Evolution of maize climate productivity and its response to climate change in Hei longjiang Province, China. Chinese Journal of Applied Ecology. Vol.27(2016)No .8,p.2561.(in Chinese)

[7] Y.J. Liuand T.Pan. Spatial simulation of surface solar radiation resources in China[J].Joural of Natural Resources.Vol.27(2012)No .8,p.1392.(in Chinese)

[8] Q.H. He and Y. Xie . Study on the climatology calculation method of solar radiation in China[J].Joural of Natural Resources, Vol.25(2010)No 2,p.308.(in Chinese)

[9] W. Cao and S.H. Shen. Study on the calculation method of sun solar radiation in China[J].Journal of Nanjing Institute of Meteorology.Vol.31(2008)No 4,p.587.(in Chinese)

[10] X.H. Ju , Q.P. Tu and Q.X. Li.A rediscussion on the calculation method of total solar radiation climatology in China[J].Journal of Nanjing Institute of Meteorology.Vol.28(2005)No 4,p.516.(in Chinese)

[11]X.G. Zhang. Impacts of climate changes on crop potential productivity in northeast China (MS., Hunan Agricultural University, China 2007),p.37.(in Chinese) 